\title{
Toric Intraocular Lens Malposition Corrected by Lens Repositioning to Manifest Refractive Cylinder Axis in Patient with Irregular Astigmatism Due to Corneal Scar
}

\author{
Riley Sanders ${ }^{1,2}$, Johnny Gayton ${ }^{1,2}$ \\ ${ }^{1}$ Mercer University School of Medicine, Macon, USA \\ ${ }^{2}$ Eyesight Associates, Warner Robins, USA \\ Email: sanders r@med.mercer.edu
}

Received 29 January 2015; accepted 28 April 2015; published 30 April 2015

Copyright (C) 2015 by authors and Scientific Research Publishing Inc.

This work is licensed under the Creative Commons Attribution International License (CC BY). http://creativecommons.org/licenses/by/4.0/

\section{(c) (i) Open Access}

\begin{abstract}
A case is presented of a patient with an unexpected poor visual result and subsequent correction following cataract removal surgery via phacoemulsification and intraocular lens implantation using a toric intraocular lens implant (IOL). The initial operation resulted in an uncorrected vision of 20/100 (0.70 logMAR). Retrospective analysis of the patient's corneal topography revealed irregular astigmatism secondary to remote trauma to the cornea. The cylinder axis on manifest refraction (MR) was significantly different from measured keratometry, so a second procedure was performed to align the cylinder axis of the IOL with the steep axis on MR. This repositioning procedure improved visual outcome to a final uncorrected vision of 20/25 (0.10 logMAR) and best corrected acuity of $20 / 20(0.0 \log M A R)$.
\end{abstract}

\section{Keywords}

Irregular Astigmatism, Toric IOL, IOL, Toric, Malposition, Reposition

\section{Introduction}

Toric intraocular lens implants (IOLs) used in cataract surgery are used to correct both sphere and cylinder refractive error, and are designed to neutralize preexisting corneal astigmatism. They have the potential to improve visual outcomes of astigmatic eyes in patients with regular or irregular astigmatism [1]. The Acrysof ${ }^{\circledR}$ Toricsingle-piece lens implant has demonstrated efficacy in refractive correction and minimal postoperative rotation [2]. 
Accurate biometry is crucial for calculating refractive power of the implant lens, and keratometry serves as the basis for determining placement of the toric lens's cylinder axis [3]. For reassurance of accurate and precise measurements, one may utilize several methods of keratometry including manual keratometers, optical low coherence reflectometry devices, and computerized corneal topography [4] [5].

Occasionally a patient may experience disturbing residual astigmatism following implantation of a toric IOL due to malposition on implantation, rotation of the IOL [6], surgically induced astigmatism [7], or ocular residual astigmatism not measurable preoperatively [8] [9]. Malposition can reduce the astigmatic correction, alter the astigmatic axis, and induce hyperopic spherical change [10].

In this case study, an astigmatic patient with misleading keratometry due to corneal irregularity from remote ocular trauma received a toric implant and was initially displeased with the result. Pre- and postoperative MR cylinder axis was found to differ from objective keratometry. Corneal topography revealed an unusual pattern of astigmatism created by the scarred area. Realignment of the toric IOL using the preoperative MR cylinder axis reduced astigmatism, improving vision and patient satisfaction.

\section{Case History}

The patient was a healthy 67-year-old Caucasian male with compound myopic astigmatism presenting with gradual decrease in best corrected visual acuity over a period of three years. His past history was significant for an injury to his eyes while grinding metal in the 1970s which required removal of metallic foreign bodies from both eyes and scarred the left cornea. His left eye's uncorrected vision was count-fingers at 5 feet (1.5 meters) with best corrected visual acuity of 20/40 (0.3 logMAR). His left eye manifest refraction was $-8.50+1.50 \times$ $032^{\circ}$. On exam he was found to have a well-healed stromal scar on the superior temporal left cornea, combined cataracts in both lenses, and no evidence of other ocular pathology. He was scheduled for phacoemulsification with IOL implantation, and a toric implant was chosen to correct astigmatism.

Ocular biometry for lensectomy and lens implantation was obtained with a manual keratometry $\left(\right.$ Topcon $\left.^{\circledR}\right)$, low coherence reflectometry (Zeiss IOL Master ${ }^{\circledR}$ ) and computerized corneal topography (Zeiss Atlas ${ }^{\circledR}$ ). The meridian of the flat and steep keratometry axis measured consistently between methods (steep axis range: $122^{\circ}$ $135^{\circ}$ ), although the cylinder power measured inconsistently and ranged from 0.75 to 2.25 diopters in the left eye depending on the method used (Table 1).

The Acrysof ${ }^{\circledR}$ Toric SN60T4 with 2.25 D cylinder power was selected to correct the patient's compound myopic astigmatism in the left eye. Measurements from manual keratometry and the IOL master were entered into The Acrysof Toric IOL Calculator ${ }^{\mathrm{TM}}$ online [11]. The software suggested the IOL be positioned with the steep axis at $120^{\circ}$.

The cataract was extracted via phacoemulsification through a temporal self-sealing incision and anterior capsulorhexis by forceps. An Acrysof Toric SN60T4 intraocular lens implant was inserted into the capsule and positioned at an axis of $120^{\circ}$ without procedural complication.

Postoperatively, the patient's left eye uncorrected vision was 20/100 (0.70 logMAR) and best corrected acuity was 20/25 (0.10 logMAR) with a MR of $-1.50+2.50 \times 032$. Examination and slit lamp photography confirmed the IOL to be in stable position with steep axis markings at $120^{\circ}$. Corneal topography was notable for a steep area surrounding his old corneal scar and separate from the bow-tie pattern of astigmatism across the central cornea (Figure 1). Due to the increase in manifest astigmatism at the same manifest axis, the surgeon decided to reopen the incision and reposition the lens to $30^{\circ}$ based on his MR.

Following the repositioning, the patient's left eye saw 20/25 (logMAR 0.10) uncorrected with best corrected acuity of 20/20 (logMAR 0.0 ) with a MR of $-0.75+0.75 \times 005$. The patient was pleased with this significant improvement from his prior vision. Informed consent was obtained prior to reporting the case.

Table 1. Preoperative keratometry measurements.

\begin{tabular}{|c|c|c|c|c|c|}
\hline Keratometry & Flat K & Flat axis & Steep K & Steep axis & Avg. $\Delta \mathrm{D}$ \\
\hline Manual (Marco K1) & $46.75 \mathrm{D}$ & $53^{\circ}$ & $47.25 \mathrm{D}$ & $127^{\circ}$ & +0.75 D@127º \\
\hline Zeiss IOL Master ${ }^{\circledR}$ (3 consecutive trials) & $45.59 \mathrm{D} \pm 0.03$ & $58^{\circ} \pm 1.63^{\circ}$ & $47.82 \mathrm{D} \pm 0.06$ & $122^{\circ} \pm 1.63^{\circ}$ & +2.24 D@122 \\
\hline Zeiss Atlas ${ }^{\circledR}$ v. A12.2 (3 consecutive trials) & $45.87 \mathrm{D} \pm 0.10$ & $45^{\circ} \pm 12.7^{\circ}$ & $46.99 \mathrm{D} \pm 0.10$ & $135^{\circ} \pm 12.7^{\circ}$ & +1.12D@134.7 \\
\hline
\end{tabular}




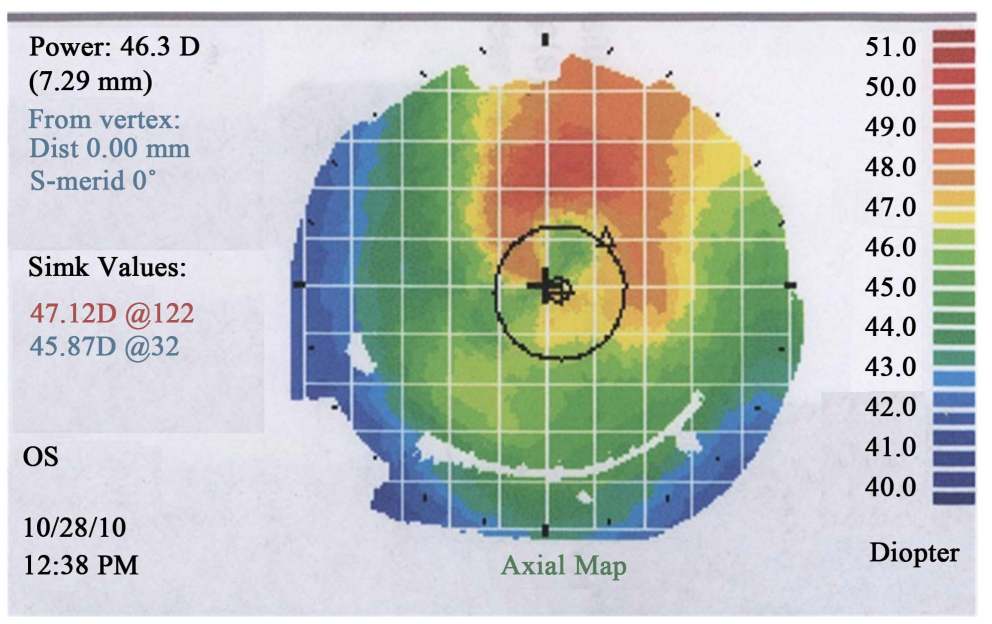

Figure 1. Corneal topography of OS showing superotemporal steepening outside of central bow-tie pattern astigmatism.

\section{Discussion}

Despite having high cylinder in his preoperative MR, this patient was a questionable candidate for a toric IOL implantation due to his unique corneal curvature secondary to scarring. It is imperative to obtain accurate and reproducible preoperative measurements when calculating IOL power; one must also consider patient preference and the effects of other ocular pathology.

This patient preferred a relatively high cylinder power in his corrective spectacles, so it seemed sensible to try a toric IOL. When keratometry consistently found a cylinder axis conflicting with the MR, the IOL implantation axis was planned for the keratometry axis rather than the MR axis. Positioning the steep meridian of a toric IOL along the keratometry axis is common practice because manifest astigmatism is understood to be the result of interaction between corneal curvature and internal factors including lenticular astigmatism [12]. Removing the crystalline lens removes its effect on manifest astigmatism, and thus corneal measurements are the primary concern when designating an axis for a toric lens implant.

This patient's measured keratometry was misleading and corneal topography provided a likely explanation. A small central bow-tie pattern was present and repeatedly measured while the scar position appeared to have been the true dominant astigmatic presence in the left cornea (Figure 1). As a result, the postoperative astigmatism after the first operation was worse by 1.00 diopter. Precisely calculating corneal refractive power is challenging since keratometry does not directly measure corneal power, and can be confounded by surgical or traumatic scars which change the relationship between the anterior and posterior cornea, altering the corneal refractive index [12]. Newer modalities such as rotating Scheimpflug imaging aim to improve measurement by scanning the anterior and posterior corneal surface [13].

The combined optical effects of the cornea and toric IOL can be considered as two obliquely crossed spherocylinders combined to form a new spherocylinder and more complex refractive status due to irregularities and optical aberrations. When there is an unsatisfactory refractive result following toric IOL implantation, options to correct the error include corrective lenses, laser vision correction, repositioning, or IOL exchange depending on the situation [10]. A repositioning procedure was appropriate in this case because of the high postoperative compound astigmatism. Repositioning to the MR axis resulted in improvement in this patient's vision. Cataract surgeons considering toric IOL implants should be cautious with patients having corneal scarring due to the risk of unexpected refractive changes postoperatively.

\section{References}

[1] Bauer, N.J.C., de Vries, N.E., Webers, C.A.B., Hendrikse, F. and Nuijts, R.M.M.A. (2008) Astigmatism Management in Cataract Surgery with the AcrySoftoric Intraocular Lens. Journal of Cataract Refractive Surgery, 34, 1483-1488. http://dx.doi.org/10.1016/j.jcrs.2008.05.031

[2] Nuijts, R.M.M.A., Bauer, N.J.C. and Visser, N. (2009) Optimize Surgical Results with Toric IOLs. Cataract and Re- 
fractive Surgery Today Europe, July/August, 17-25.

[3] Koshy, J.J., Nishi, Y., Hirnschall, N., Crnej, A., Gangwani, V., Maurino, V. and Findl, O. (2010) Rotational Stability of a Single-Piece Toric Acrylic Intraocular lens. Journal of Cataract Refractive Surgery, 36, 1665-1670. http://dx.doi.org/10.1016/j.jcrs.2010.05.018

[4] Shirayama, M., Wang, L., Weikert, M.P. and Koch, D.D. (2009) Comparison of Corneal Powers Obtained from 4 Different Devices. American Journal of Ophthalmology, 148, 528-535. http://dx.doi.org/10.1016/j.ajo.2009.04.028

[5] Vogel, A., Dick, H.B. and Krummenauer, F. (2001) Reproducibility of Optical Biometry Using Partial Coherence Interferometry: Intraobserver and Interobserver Reliability. Journal of Cataract Refractive Surgery, 27, 1961-1968. http://dx.doi.org/10.1016/S0886-3350(01)01214-7

[6] Shah, G.D., Praveen, M.R., Vasavada, A.R., Vasavada, V.A., Rampal, G. and Shastry, L.R. (2012) Rotational Stability of a Toric Intraocular Lens: Influence of Axial Length and Alignment in the Capsular Bag. Journal of Cataract Refractive Surgery, 38, 54-59. http://dx.doi.org/10.1016/j.jcrs.2011.08.028

[7] Tejedor, J. and Perez-Rodriguez, J.A. (2009) Astigmatic Change Induced by 2.8-mm Corneal Incisions for Cataract Surgery. Investigative Ophthalmology and Visual Science, 50, 989-994. http://www.iovs.org/content/50/3/989.full.pdf http://dx.doi.org/10.1167/iovs.08-2778

[8] Alpins, N., Ong, J.K.Y. and Stamatelatos, G. (2014) Refractive Surprise after Toric Intraocular Lens Implantation: Graph Analysis. Journal of Cataract Refractive Surgery, 40, 283-294. http://dx.doi.org/10.1016/j.jcrs.2013.06.029

[9] Koch, D.D., Ali, S.F., Weikert, M.P., Shirayama, M., Jenkins, R. and Wang, L. (2012) Contribution of the Posterior Corneal Astigmatism to Total Corneal Astigmatism. Journal of Cataract Refractive Surgery, 38, 2080-2087. http://dx.doi.org/10.1016/j.jcrs.2012.08.036

[10] Alcon, Inc. AcrySofToric IOL Web Based Calculator. www.acrysoftoriccalculator.com

[11] Jin, H., Limberger, I.J., Ehmer, A., Guo, H. and Auffarth, G.U. (2010) Impact of Axis Misalignment of Toric Intraocular Lenses on Refractive Outcomes after Cataract Surgery. Journal of Cataract Refractive Surgery, 36, 2061-2072. http://dx.doi.org/10.1016/j.jcrs.2010.06.066

[12] Mohammadi, S., Tahvildari, M. and Z-Mehrjardi, H. (2012) Physiology of Astigmatism, Astigmatism—Optics, Physiology and Management. In: Goggin, M., Ed., InTech, 1-13. http://www.intechopen.com/books/astigmatism-optics-physiology-and-management

[13] Lee, A.C., Qazi, M.A. and Pepose, J.S. (2008) Biometry and Intraocular Lens Power Calculation. Current Opinion in Ophthalmology, 19, 13-17. http://dx.doi.org/10.1097/ICU.0b013e3282f1c5ad 